\title{
High-throughput sequencing of the DBA/2J mouse genome
}

\author{
Xusheng Wang ${ }^{1}$, Richa Agarwala ${ }^{2}$, John A Capra ${ }^{3}$, Zugen Chen", Deanna M Church², Daniel C Ciobanu', \\ Zhengsheng Li ${ }^{1}$, Lu Lu', Khyobeni Mozhui', Megan K Mulligan', Stanley F Nelson ${ }^{4}$, Katherine S Pollard ${ }^{3}$, \\ Williams L Taylor', Donald B Thomason', Robert W Williams ${ }^{1 *}$
}

From UT-ORNL-KBRIN Bioinformatics Summit 2010

Cadiz, KY, USA. 19-21 March 2010

\section{Background}

The DBA/2J mouse is not only the oldest inbred strain, but also one of the most widely used strains. DBA/2J exhibits many unique anatomical, physiological, and behavior traits. In addition, $\mathrm{DBA} / 2 \mathrm{~J}$ is one parent of the large BXD family of recombinant inbred strains [1]. The genome of the other parent of this BXD familyC57BL/6J-has been sequenced and serves as the mouse reference genome [2]. We sequenced the genome of DBA/2J using SOLiD and Illumina high throughput short read protocols to generate a comprehensive set of $\sim 5$ million sequence variants segregating in the BXD family that ultimately cause developmental, anatomical, functional and behavioral differences among these $80+$ strains.

\section{Results}

We generated approximately 13.2 and $38.9 \times$ whole-genome short reads of DBA/2J females using Illumina GA2 and ABI SOLiD massively parallel DNA sequencing platforms. Comparing to the C57BL/6J reference genome sequence, we identified over 4.5 million single nucleotide polymorphisms (SNPs), including 84 nonsense and $\sim 11,000$ missense mutations, $78 \%$ of which are novel. We also detected $\sim 568,000$ insertions and deletions (indels) within single short reads and $\sim 9,400$ between mate-paired reads. Approximately 300 inversions were detected by SOLiD mate-pair reads, 46 of which span at least one exon. In addition, we identified $\sim 22,000$ copy number variants (CNVs) in the range of $1 \mathrm{~Kb}$ to $100 \mathrm{~Kb}$ (Figure 1).

\footnotetext{
* Correspondence: rwilliam@nb.uthsc.edu

${ }^{1}$ University of Tennessee Health Science Center, Memphis, TN 38163, USA
}

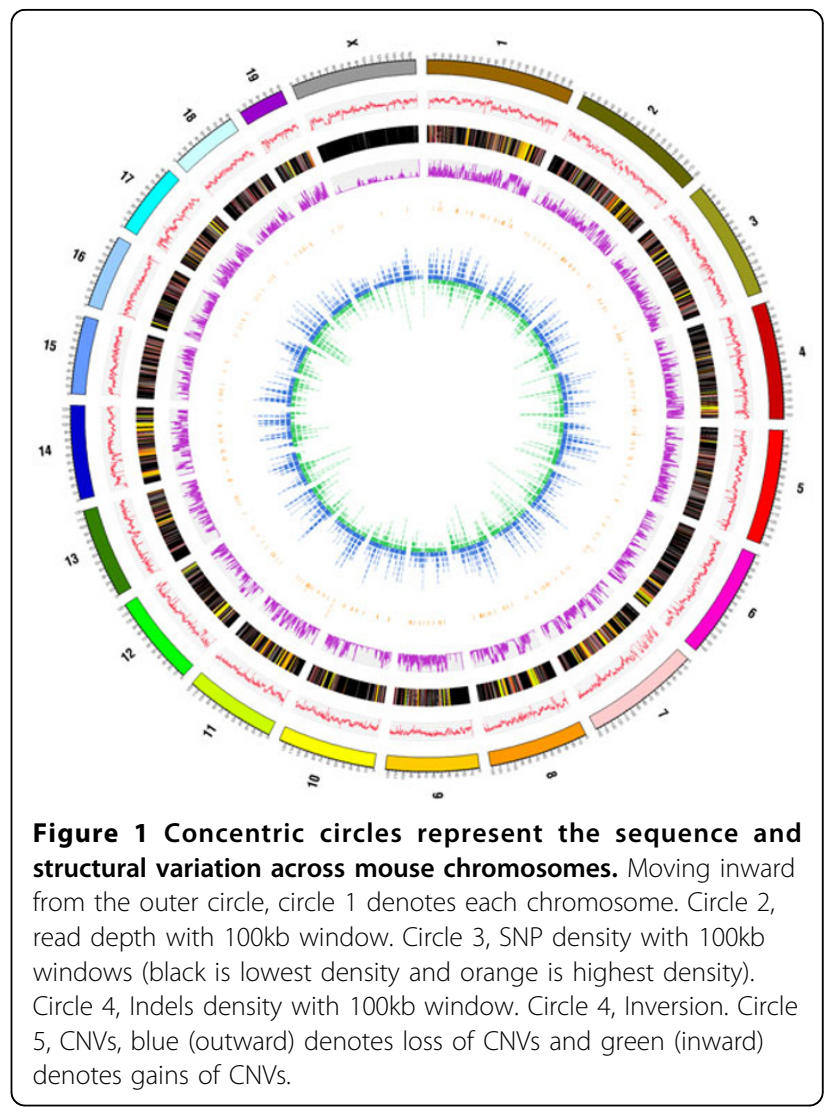

\section{Conclusion}

Our study generates the first consensus sequence for the $\mathrm{DBA} / 2 \mathrm{~J}$ and creates a compendium of sequence and structural variations that will be used by the community of researchers who study complex traits in mouse models. The sequence data provide a novel resource with which to initiate reverse genetic analysis of complex 
traits, particularly by exploiting strong alleles (premature stop codons, frame-shift mutations, and deletion) that differentially affect members of the BXD strain family. The DBA/2J genome is also an essential prerequisite to unbiased alignment of RNA-seq and ChIP-seq data generated using BXD strains and any other cross involving these two common parental strains.

\section{Author details}

${ }^{1}$ University of Tennessee Health Science Center, Memphis, TN 38163, USA.

${ }^{2}$ National Center for Biotechnology Information, National Library of Medicine, National Institutes of Health, Bethesda, MD 20894, USA. ${ }^{3}$ Gladstone Institutes, University of California, San Francisco, CA 94158, USA. ${ }^{4}$ University of California, Los Angeles, CA 90095, USA. ${ }^{5}$ University of Nebraska, Lincoln, NE 68588, USA.

Published: 23 July 2010

\section{References}

1. Peirce $J L, L u L, G u J$, Silver $L M$, Williams RW: A new set of BXD recombinant inbred lines from advanced intercross populations in mice. BMC genetics 2004, 5:7.

2. Waterston RH, Lindblad-Toh K, Birney E, Rogers J, Abril JF, Agarwal P, Agarwala R, Ainscough R, Alexandersson M, An P: Initial sequencing and comparative analysis of the mouse genome. Nature 2002, 420(6915):520-562.
Submit your next manuscript to BioMed Central and take full advantage of:

- Convenient online submission

- Thorough peer review

- No space constraints or color figure charges

- Immediate publication on acceptance

- Inclusion in PubMed, CAS, Scopus and Google Scholar

- Research which is freely available for redistribution

Submit your manuscript at www.biomedcentral.com/submit 